\title{
PERUBAHAN BANGUNAN TRADISIONAL KARO DENGAN PENDEKATAN ARSITEKTUR VERNAKULAR \\ (Studi Kasus : Rumah Tinggal Masyarakat Karo di Desa Doulu, Berastagi, Kabupaten Tanah Karo)
}

\author{
Rina Saraswaty ${ }^{1}$, Suprayitno ${ }^{2}$ \\ 1,2Dosen Pengajar Program Studi Arsitektur, Fakultas Teknik, UMA, Medan \\ Surel : rinasaraswaty@yahoo.co.id \\ Diterima : 18 Oktober 2017; Disetujui : 25 Oktober 2017
}

\begin{abstract}
ABSTRAK
Rumah tradisional Karo merupakan salah satu kebudayaan peninggalan nenek moyang suatu masyarakat dari masa lalu, dikenal dengan nama Siwaluh Jabu. Dinamakan Siwaluh Jabu karena rumah tersebut dihuni oleh delapan kepala keluarga. Rumah inilah yang menjadi suatu bukti bagi kita bahwa keterbatasan pengetahuan bukanlah suatu hambatan untuk melakukan sesuatu. Namun pada perkembangannya saat ini, rumah tinggal masyarakat tradisional Karo telah mengalami banyak perubahan, baik dalam bentuk, ruang maupun penggunaan ornamen dan bahan bangunan. Salah satu faktor yang mempengaruhi perubahan bentuk dan ukuran bangunan rumah tinggal masyarakat Karo tersebut adalah adanya perubahan pola ruang. Walaupun penelitian tentang rumah tradisional Karo ini telah banyak dilakukan, namum penelitian tentang rumah tradisional Karo dengan perubahan pola ruang sebagai salah satu faktor penyebab terjadinya perubahan bentuk dan ukuran bangunan sejauh ini belum pernah dilakukan. Lokasi penelitian di Desa Doulu, Berastagi, Kabupaten Tanah Karo. Penelitian ini bertujuan untuk mengkaji faktor yang penelitian tentang perubahan dengan metode pendekatan arsitektur vernakular melalui pengamatan dan observasi langsung terhadap obyek penelitian. Adapun urgensi penelitian ini diharapkan dapat menjadi informasi dan pedoman pada penelitian selanjutnya yang berkaitan dengan pola pemukiman masyarakat Karo. Luaran penelitian berupa artikel ilmiah yang dipublikasikan pada Jurnal lokal berISSN, dan garis besar materi pembelajaran pada pendidikan Arsitektur, khususnya mata kuliah Teori Arsitektur I Perkembangan Arsitektur II dan Arsitektur Nusantara.
\end{abstract}

Kata Kunci : arsitektur vernacular, masyarakat karo, perubahan pola ruang, rumah tinggal tradisional,

\begin{abstract}
Karo traditional house is one of the ancestral heritage culture of a society from the past, known by the name of Siwaluh Jabu. Named Siwaluh Jabu because the house is inhabited by eight families. It is this house that proves to us that the limitation of knowledge is not an obstacle to doing something. But in its current development, the homes of Karo traditional society have undergone many changes, both in the form, space and the use of ornaments and building materials. One of the factors influencing the change of shape and size of residential building of Karo people is the change of spatial pattern. Although research on Karo traditional house has been done a lot, but the research on Karo traditional house with the change of spatial pattern as one of the factors causing the change of shape and the size of the building so far has never been done.Research location in Doulu Village, Berastagi, Tanah Karo District. This study aims to examine the factors that research on changes with the approach method of vernacular architecture through observation and direct observation of the object of research. The urgency of this research is expected to become information and guidance on subsequent research relating to the pattern of settlement Karo society. The research output is in the form of scientific articles published in local journal's ISSN, and outline of learning materials on the education of Architecture, especially the subjects of Teori Arsitektur I , Perkembangan Asitektur II and Arsitektur Nusantara
\end{abstract}

Keywords: change of room pattern, karo society, traditional residence, vernacular architecture 


\section{Pendahuluan}

Kajian mengenai identitas dalam arsitektur, merupakan sebuah fenomena yang selalu menarik untuk diperbincangkan. Bukan hanya mengenai identitas arsitektur Indonesia, tapi permasalahan identitas ini telah mulai dipertanyakan pada tingkat arsitektur kedaerahan. Adanya istilah arsitektur tradisional dan arsitektur vernakular merupakan sebuah wacana yang berhubungan dengan kajian dalam arsitektur kedaerahan tersebut. Sampai saat ini, kedua istilah tersebut masih belum ada pendapatpendapat yang secara tegas memberikan batasan yang antara keduanya. Secara gamblang kedua istilah ini sudah lama digunakan didalam keseharian kita, tetapi yang mana yang merupakan contoh arsitektur tradisional serta yang mana yang tergolong kedalam arsitektur vernakular masih belum terdefinisi dengan jelas.

Kebudayaan Batak Karo merupakan suatu hasil karya dari nenek moyang suku Batak Karo pada zaman dulu yang telah membuktikan bahwa keterbatasan wawasan pengetahuan tidak menghalangi mereka untuk berkarya dan menghasilkan sesuatu yang berguna bagi anak cucu mereka sampai saat ini, dan juga oleh pemerintah daerah Sumatera Utara telah dijadikan salah satu objek wisata di daerah Batak Karo - Sumatera Utara. Siwaluh Jabu, itulah nama dari rumah tradisional Batak Karo yang didiami oleh delapan kepala keluarga. Rumah inilah yang menjadi suatu bukti bagi kita bahwa keterbatasan pengetahuan bukanlah suatu hambatan untuk melakukan sesuatu.

Rumah tradisional Karo didesain tahan terhadap gempa dengan usia bangunan mencapai ratusan tahun dan dalam pembuatannya tidak memakai paku. Di samping itu peran guru (dukun) sangat penting terkait letak rumah tradisional yang akan didirikan. Masyarakat Karo percaya akan sifat tanah, bahwa ada tanah yang baik dan tidak baik untuk bermukim di atasnya. Dapat dikatakan seluruh proses dari awal sampai peresmian (mengket) rumah tidak lepas dari nasehat dan peran guru.

Adapun tujuan dari penelitian ini adalah untuk mengkaji perubahan bangunan rumah tinggal masyarakat tradisional Karo yang berkembang ditinjau dari pola ruang yang merubah bentuk dan ukuran bangunan, sehingga diperoleh faktor-faktor yang mempengaruhi perubahan tersebut.
Arsitektur tradisional sebagai salah satu unsur kebudayaan sebenarnya tumbuh dan berkembang seiring dengan pertumbuhan suatu suku bangsa. Oleh karena itu, tidaklah berlebihan jika dikatakan bahwa arsitektur tradisional merupakan suatu hal yang dapat memberikan ciri serta identitas dari suatu suku bangsa sebagai pendukung suatu kebudayaan tertentu. Sementara itu batasan tentang arsitektur tradisional telah banyak diberikan oleh para ahli. Batasan-batasan tersebut secara keseluruhan dapat disimpulkan bahwa arsitektur tradisional merupakan suatu bangunan yang bentuk, struktur, fungsi, ragam hias, dan cara membuatnya diwariskan dari satu generasi ke generasi berikutnya, serta dapat dimanfaatkan sebagai tempat untuk melaksanakan segala aktivitas kehidupan.

\section{Pembahasan}

\subsection{Arsitektur Vernakular}

Menurut Turan dalam buku Vernacular Architecture (Wiranto, 1999), arsitektur vernakular adalah arsitektur yang tumbuh dan berkembang dari arsitektur rakyat yang lahir dari masyarakat etnik dan berjangkar pada tradisi etnik, serta dibangun oleh tukang berdasarkan pengalaman (trial and error), menggunakan teknik dan material lokal serta merupakan jawaban atas setting lingkungan tempat bangunan tersebut berada dan selalu membuka untuk terjadinya transformasi. Lebih lanjut dalam buku yang sama, Turan telah mencoba mengklasifikasikan arsitektur vernakular kedalam beberapa tinjauan, yaitu: 1.Arsitektur vernakular sebagai produk. 2.Arsitektur vernakular sebagai proses. 3.Arsitektur vernakular dari tinjauan filosofis.

4.Arsitektur vernakular sebagai ilmu pengetahuan.

Romo Mangunwijaya dalam buku Wastu Citra juga memberikan pendapat yang hampir senada mengenai definisi dari arsitektur vernakular itu sendiri. Menurut beliau, arsitektur vernakular itu adalah pengejawantahan yang jujur dari tata cara kehidupan masyarakat dan merupakan cerminan sejarah dari suatu tempat. Jadi arsitektur vernakular bukanlah semata-mata produk hasil dari ciptaan manusia saja, tetapi yang lebih penting adalah hubungan antara manusia dengan lingkungannya.

Arsitektur vernakular merupakan bentuk perkembangan dari arsitektur tradisional, yang mana arsitektur tradisional sangat lekat dengan tradisi yang masih hidup, tatanan kehidupan masyarakat, wawasan 


\section{Perubahan Bangunan Tradisional Karo Dengan Pendekatan Arsitektur Vernakular \\ (Studi Kasus : Rumah Tinggal Masyarakat Karo Di Desa Doulu, Berastagi, Kabupaten Tanah Karo)}

masyarakat serta tata laku yang berlaku pada kehidupan sehari-hari masyarakatnya secara umum, sedangkan arsitektur vernakular merupakan transformasi dari situasi kultur homogen ke situasi yang lebih heterogen dan sebisa mungkin menghadirkan citra serta bayang-bayang realitas dari arsitektur tradisional itu sendiri.

Selain sebagai arsitektur vernakular, istilah arsitektur tradisional juga merupakan istilah yang sering muncul didalam kalangan masyarakat kita. Masyarakat tidak mengenal arsitektur vernakular melainkan arsitektur tradisional, dimana yang dimaksud dengan arsitektur tradisional itu adalah arsitektur yang dibuat dengan cara yang sama secara turun temurun dengan sedikit atau tanpa adanya perubahan-perubahan yang signifikan pada bangunan tersebut. Arsitektur tradisional ini biasa disebut dengan arsitektur kedaerahan.

Bruce Allsopp (1976) berpendapat bahwa arsitektur vernakular adalah sebuah cara mendesain yang umum diperoleh/ditemukan pada arsitektur rakyat. Menurut Amos Rapoport dalam buku House Form and Culture, Rapoport mengidentifikasi lanjut bahwa jenis Arsitektur Vernakular yang ada dapat dipisahkan sebagai Vernakular Tradisional dan Vernakular Modern. Terjadinya bentuk-bentuk atau model Vernakular disebabkan oleh enam faktor yang dikenal sebagai modifying factor diantaranya adalah, faktor bahan, metode konstruksi, faktor teknologi, faktor iklim, pemilihan lahan dan faktor sosial-budaya

\subsection{Bangunan Tradisonal Karo Siwaluh Jabu}

Masyarakat Karo menerapkan arsitektur tradisionalnya pada bangunan hunian tempat tinggalnya (merga-silima.blogspot.co.id) tersebut dikenal dengan nama Siwaluh Jabu. Siwaluh Jabu memiliki pengertian sebagai sebuah rumah yang didiami delapan keluarga. Dimana masing-masing keluarga memiliki peran tersendiri di dalam rumah tersebut. Penempatan keluarga-keluarga dalam Rumah Adat Karo Sumatera Utara ditentukan oleh adat Karo. Secara garis besar rumah adat ini terdiri atas jabu jahe (hilir) dan jabu julu (hulu). Jabu jahe juga dibagi menjadi dua bagian, yaitu jabu ujung kayu dan jabu rumah sendipar ujung kayu.

Rumah Adat Karo Sumatera Utara terdiri atas delapan ruang dan dihuni oleh delapan keluarga. Sementara dalam rumah ini hanya ada empat dapur. Masing-masing jabu dibagi dua sehingga terbentuk jabu-jabu sedapuren bena kayu, sedapuren ujung kayu, sedapuren lepar bena kayu, dan jabu sedapuren lepar ujung kayu. Rumah ini bertiang tinggi dan satu rumah biasanya dihuni atas satu keluarga besar yang terdiri dari 4 sampai 8 keluarga Batak. Di dalam rumah tak ada sekatan satu ruangan lepas. Namun pembagian ruangan tetap ada, yakni di batasi oleh garis-garis adat istiadat yang kuat, meski garis itu tak terlihat. Masingmasing ruangan mempunyai nama dan siapa yang harus menempati ruangan tersebut, telah ditentukan pula oleh adat.

Urutan ruangan dalam rumah Siwaluh jabu adalah sebagai berikut:

a. Jabu bena kayu yaitu ruangan di depan sebelah kiri, didiami oleh pihak marga tanah dan pendiri kampung. Ia merupakan pengulu atau pemimpin rumah tersebut. Jabu sedapur bena kayu yaitu ruangan berikutnya yang satu dengan jabu bena kayu, juga dinamai Sinenggel-nenggel. Ruang ini didiami oleh pihak Senina yakni saudarasaudaranya yang bertindak sebagai wakil pemimpin rumah tersebut. Sedapat artinya satu dapur, karena setaip 2 ruangan maka di depannya terdapat dapur yang dipakai untuk 2 keluarga.

b. Jabu ujung kayu, dinamai Jabu Sungkun Berita, didiami oleh anak Beru Toa, yang bertugas memecahkan setiap masalah yang timbul.

c. Jabu sedapur ujung kayu yaitu ruangan sedapur dengan jabu ujung kayu, dinamai Jabu Silengguri. Jabu ini didiami oleh anak beru dari jabu Sungkun Berita.

d. Jabu lepan bena kayu, yakni ruangan yang terletak berseberangan dengan jabu bena kayu, dinamai jabu simengaloken didiami oleh Biak Senina.

e. Jabu sedapur lepan bena kayu yaitu ruangan yang sedapur dengan jabu lepan bena kayu, didiami oleh Senina Sepemeren atau Separiban.

f. Jabu lepan ujung kayu, didiami oleh Kalimbuh yaitu pihak pemberi gadis, ruangan ini disebut Jabu Silayari.

g. Jabu sedapur lepan ujung kayu yaitu ruangan yang sedapur dengan jabu lepan ujung kayu. Rumah Adat Karo Sumatera Utara, ruangan ini didiami oleh Jabu Simalungun minum, didiami oleh Puang 


\section{Rina Saraswaty - Suprayitno}

Kalimbuh yaitu Kalimbuh dari jabu silayari. Kedudukan Kalimbuh ini cukup dihormati didalam adat.

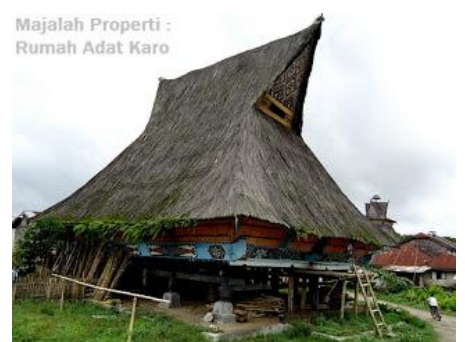

Gambar 1. Bangunan rumah tradisional karo
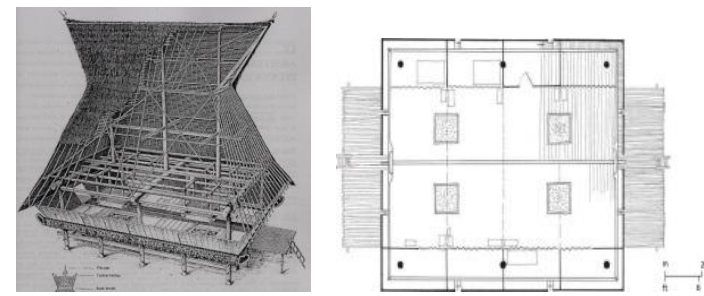

Gambar 2. Struktur bangunan dan denah Jabu

Tabel 1. Bentuk rumah siwalah jabu

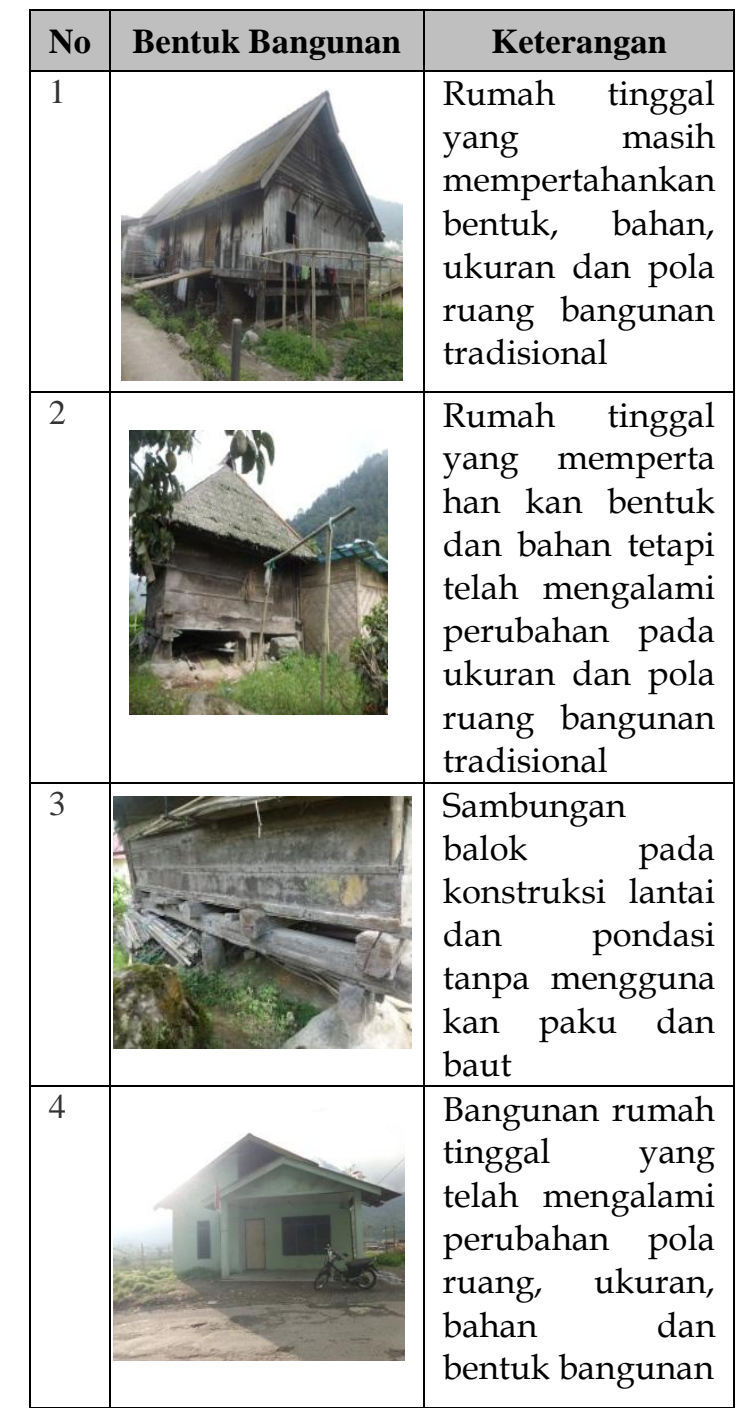

Dari analisa diatas dapat dilihat bahwa perubahan terhadap bangunan rumah tinggal masyarakat karo ditinjau dari arsitektur vernakular dari sisi pola ruang dapat dikelompokkan sebagai berikut:

1. Bangunan rumah tinggal yang mempertahankan pola ruang sehingga bentuk dan ukurannya juga sama dengan bangunan rumah tradisional karo begitu juga dengan penggunaan bahan tanpa menggunakan sekat dalam ruangan.

2. Bangunan dengan pola ruang tetap mengacu kepada bangunan tradisional tanpa sekat ruangan namun mengalami perubahan ukuran karena tidak ditempati oleh delapan keluarga tetapi dihuni oleh satu atau dua keluarga saja. Sehingga ukuran bangunan mengalami perubahan semakin kecil dari ukuran bangunan tradisional karo. Namun penggunaan bahan bangunan tetap sama.

3. Bangunan dengan tetap mempertahankan pola ruang dan ukuran sehingga bentuk bangunan sama dengan bangunan tradisional, namun mengalami perubahan dalam penggunaan bahan bangunan.

4. Bangunan yang telah mengalami perubahan baik pola ruang, ukuran, bentuk maupun penggunaan bahan. Ruangan telah memakai sekat permanen yang membatasi antara ruang satu dengan ruang yang lainnya

\section{Simpulan dan Saran}

\subsection{Simpulan}

Dari hasil obeservasi lapangan dan analisa, dapat diambil simpulan bahwa perubahan yang terjadi pada bangunan rumah tinggal masyarakat karo pada saat ini dipengaruhi oleh adanya beberapa faktor, yaitu faktor sosial ekonomi dan budaya yang semakin baik menyebabkan perubahan wawasan berpikir yang lebih luas akibat dari adanya faktor pendidikan yang semakin baik disamping adanya kemajuan ilmu dan teknologi. Tingkat sosial budaya yang semakin baik sebagai salah satu faktor yang mempengaruhi perubahan tersebut. Namun perubahan tetap mengacu terhadap pola dasar ruang bangunan tradisional. Secara umum arsitektur vernakular pada bangunan rumah tinggal tradisional masyarakat karo tetap menempel pada bangunan sekarang.

\subsection{Simpulan}

Perubahan pada bangunan rumah tinggal masyarakat Karo ditinjau dari pola ruang bisa terjadi namun harus tetap mempertahankan 


\section{Perubahan Bangunan Tradisional Karo Dengan Pendekatan Arsitektur Vernakular (Studi Kasus : Rumah Tinggal Masyarakat Karo Di Desa Doulu, Berastagi, Kabupaten Tanah Karo)}

pola ruang dasar bangunan tradisional yang mencerminkan kekeluargaan dan kebersamaan. Penempatan ruang-ruang yang hanya dibatasi tirai dapat diubah dengan membuat sekat agar bersifat lebih privacy namun tetap mempertahankan rasa kebersamaan.

\section{Daftar Pustaka}

Allsopp, Bruce:A Modern theory of Architecture, Routledge \& Kegan Paul Ltd, London, 1977. pp.6-9.

http://Budayakaro.blogspot.com. Kosmologi Masyarakat Karo yang Tertera pada Rumah Adatnya, 13 April 2010

http://www.rumahperumahan.com., Desain Bentuk Rumah Adat Karo dan Penjelasannya, Agustus 2016

Mangunwijaya, Romo: Wastu Citra, Gramedia, Jakarta, 1990

merga-silima.blogspot.co.id)/siwaluh-jabu-rumahadat-suku-karo

Nesbitt, Kate:Theorizing a New Agenda for Architecture, Princeton Architectural Press- New York, 1996.

Pelamonia,F:blogspot.com/2009/11/perkembanganarsitektur tradisional Karo, 23 November $\underline{2009}$

Rapoport: House, Form And Culture, PrenticeHall International, Inc., London, 1969

TantaBangun: http://tantabangun.wordpress.com, Menilik Nilai-Nilai Dalam Rumah Adat Karo"Siwaluh Jabu", 23 Mei 2010

Turan, Mete:Vernacular Architecture, Paradigma of Environmental, Response, 1990

Wiranto :Arsitektur Vernakular Indonesia: Perannya Dalam Pengembangan Diri, Jurnal DIMENSI TEKNIK ARSITEKTUR VOL. 27, NO. 2, Desember 1999: 15 - 20 